\title{
Yüzey Pürüzlülüğü Ölçme İşleminde Ölçme Belirsizliği Hesapları ve Belirsizlik Bütçesi Tablosu
}

\author{
Anıl AKDOĞAN ${ }^{* 1}$, Ali Serdar VANLI ${ }^{1}$ \\ ${ }^{1}$ Yıldız Teknik Üniversitesi, Makine Fakültesi, Makine Mühendisliği Bölümü, İstanbul
}

Geliş tarihi: 20.03.2019 Kabul tarihi: 28.06.2019

Öz

Günümüzde ölçüm sonuçlarına olan güven, ölçüm sonuçları ancak uluslararası izlenebilir olduğu sürece vardır. Uluslararası standartlar ölçüm belirsizliklerini ilgili kalite ihtiyaçlarının temel gereklilikleri olarak değerlendirmekte ve doğrulayabilmektedir. Bu çalışmada, alın frezeleme yöntemi ile elde edilmiş mamulün yüzey pürüzlülüğü ölçümü sırasında ilgili standartlara bağlı olarak ölçme belirsizliği hesaplamaları gerçekleştirilmiştir. Ölçme işlemine etkiyen en önemli hata faktörleri ile belirsizlik bütçesi tablosu oluşturulmuştur. Böylece, ölçme işlemine etki eden ve hataya sebep olan faktörlerin etkisini en az seviyeye indirmek mümkün olmakta ve ölçme işleminin doğruluğunun yüksek olduğu kanıtlanmaktadır. $\mathrm{Bu}$ uygulama için, hesaplanan birleşik ölçme belirsizliğinin müşteri beklentilerini karşıladığını görülmüştür.

Anahtar Kelimeler: Ölçme belirsizliği, Birleşik standart belirsizlik, Yüzey pürüzlülüğü ölçme, Belirsizlik bütçesi tablosu

\section{Measurement Uncertainty Calculations in Surface Roughness Measurement and Uncertainty Budget Table}

\begin{abstract}
Today, confidence in measurements is valid only as long as they are internationally traceable. International standards evaluate and verify the measurement uncertainties as the essential requirements of the relevant quality requirements. In this study, measurement uncertainty calculation was done according to the related standards for surface roughness measurement of the product obtained by end milling. The uncertainty budget table was created with the effects of the most important error factors in measurement process. Thus, it is possible to minimize the effects of errors on measurement and reach high measurement accuracy. For this application, it was seen that the calculated combined measurement uncertainty meets the customer expectations.
\end{abstract}

Keywords: Measurement uncertainty, Combined standardized uncertainty, Surface roughness measurements, Uncertainty budget table

*Sorumlu yazar (Corresponding author): Anıl AKDOĞAN, nomak@yildiz.edu.tr 


\section{GíRiş}

Metroloji bilimi birçok üretim teknolojileri için hayatidir. Çünkü imalat teknolojilerindeki gelişmelere paralel olarak ulaşılabilen hassasiyet dereceleri ancak hassas ölçme yöntemleri le doğrulanabilmektedir. Günümüzde ölçme teknikleri, imalat alanında ihtiyaç duyulan boyutsal ve geometrik ölçümlerin yanı sıra, sektördeki teknik test ve kalite kontrol uygulamalarına odaklanmaktadır. Ayrıca, ilgili standartlar ve birimler sistemlerinin kullanılması ile metrolojik uygulamalar amaçlanan ideal hedeflerine ulaşabilmektedir. Uluslararası standartlar ayrıca ölçüm cihazlarının kalibrasyonunu ve ölçüm belirsizliklerini ilgili kalite ihtiyaçlarının temel gereklilikleri olarak değerlendirmektedir.

Endüstriyel bir cihaz tarafindan yapılan bir ölçümün dünya çapında tanınması bu ölçümün ancak bir ölçüm referans zinciri ile en yüksek hassasiyetli temel ölçüm standardına bağlanmasıyla mümkün olabilmektedir. Bunu yaparak, yapılan tüm ölçümlerin ulusal ve/veya uluslararası kabul görmesi sağlanır. Kalibrasyon ve doğrulama işlemleri ülkemizde de artık büyük önem kazanmıştır. İlgili standartta kalibrasyon, belirli koşullar altında bir ölçüm cihazı veya ölçüm sistemi tarafından elde edilen değerler ile ölçümün bunlara karşılık gelen değerleri arasında bir bağlantı kurma işlemi olarak tanımlanır. Kalibrasyon ile daha az hassas bir ölçüm cihazının veya standardın ölçümü, doğruluğu kabul edilmiş bir başka standart kullanılarak gerçekleştirilir [1]. Ulusal metroloji enstitüleri, sisteme referans zinciri ile bağlı olarak en üst düzeyde çalışmaktadır. Bu kurumlar, ölçümlerin hiyerarşik bir yapıda uluslararası olarak tanınmasını sağlamak için merkezi Paris’te bulunan Uluslararası Ölçü ve Ağırlıklar Merkezi (BIPM) ile de doğrudan bağlantılidir.

Standartlar ölçüm referansı olarak kabul edilir. Metroloji ile ilgili temel standartlar, sonucun bozulmamış bir kalibrasyon zinciri aracılığıyla yapılan bir referansla ilişkili olabileceği bir ölçüm olarak tanımlanan izlenebilirliğin temelidir. Şekil 1 bu anlamda, atelye ortamında gerçekleştirilen herhangi bir ölçme işleminin uluslararası referans zinciri ile izlenebilir olması için gerekli hiyerarşik oluşumu vermektedir.

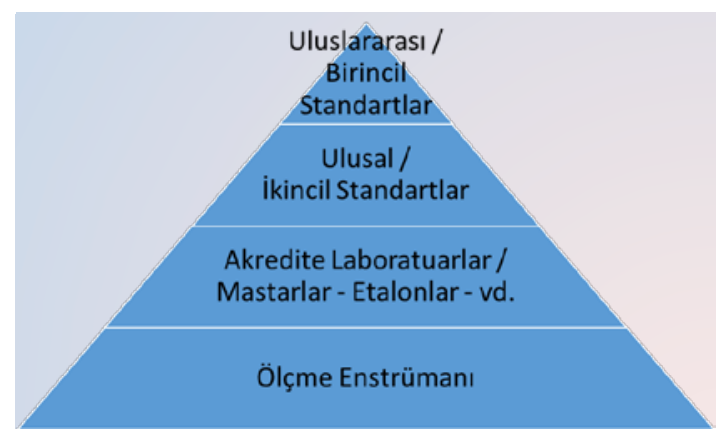

Şekil 1. Kalibrasyon hiyerarşisi

$\mathrm{Bu}$ çalışmada talaşlı imalat proseslerinden alın frezeleme yöntemi ile elde edilmiş mamulün yüzey pürüzlülüğü ölçümü sırasında ilgili standarda bağlı olarak belirsizlik hesaplaması gerçekleştirilmiştir. $\mathrm{Bu}$ çalışmada, belirlenmiş parametrelerle işlenen tek bir numunenin üzerinde, ölçme güvenilirliğini arttırmak amacıyla gerçekleştirilen tekrarlamalı ölçme işlemlerinin, ölçme belirsizliği değeri hesaplanmıştır. Amacımız, ölçme işlemine etki eden ve hataya sebep olan tüm faktörlerin etkisinin en az seviyeye indirmek ve ölçme işleminin yüksek güvenilirlikte olduğunun kanıtlanmasıdır.

\section{2. ÖLÇME BELİRSIZZLİĞi}

Uluslararası standartlara sahip birimler sistemi, BIPM tarafindan hazırlanan Uluslararası Metroloji Terimleri Sözlüğü (VIM: Vocabulary of Internatonal Metrology), ISO tarafindan hazırlanan Uluslararası Ölçme Belirsizliği Rehberi (GUM: Guide to the expression of uncertainty in measurement) standartları, ölçüm sonuçların güvenilirliğini arttırmaya yardımcı olmaktadır [2]. Bir ölçümün belirsizliği, ölçümün gerçek değerini de içeren değerler aralığını karakterize eden bir tahmindir. Ölçme belirsizliği tüm ölçüm alanları için önemli bir konudur. Çünkü tüm ölçüm işlemleri hata barındırır. Bir ölçümün hatası bilinmemektedir, çünkü kişi ölçülen miktarın gerçek değerini bilmeden hatayı bilemez. GUM, ölçümdeki belirsizliği değerlendirmek ve ifade etmek için genel kuralları tanımlar. Ölçüm belirsizliği genellikle birçok bileşeni içerir. $\mathrm{Bu}$ 
bileșenlerin bazıları, seri ölçüm sonuçlarının istatistiksel dağılımına dayanarak tahmin edilebilir ve deneysel değerler ile karakterize edilebilir niteliktedir. Diğer bileşenlerin tahminleri yalnızca temel bilgilere veya deneyimlere dayanmaktadır. Bir ölçümün ölçülenin gerçek değerine en yakın sonuç olduğu, ancak ölçüm belirsizliğinin, ilgili uluslararası standartlara göre değerlendirilmesi ve raporlanmasıyla sağlanır. Geometrik Mamül Özellikleri (GPS: Geometrical Product Specifications) standartları dâhilindeki ISO Bu amaçla 14253-2:2011 "İş parçalarının ve ölçüm cihazlarının muayenesi, Bölüm 2: GPS ölçümündeki, ölçüm cihazlarının kalibrasyonu ve ürün doğrulamasında belirsizliğin tahmini için rehber" standardı kullanıcıların temel kaynağıdır. Ölçme hataları standartta 4 farklı hata tipiyle tanımlanmaktadır. Tüm hatalar doğalarında sistematik olarak oluşmaktadır. Hata sebebi gerekli değilse veya çözünürlük seviyesi yeterli değilse sistematik olmayan hata olarak kabul edilmektedirler. İlki, sistematik hatalar ( + veya - ) boyut ve işaretlerle tanımlanır. İkincisi, rastlantısal ve sistematik hatalar, kontrol altında tutulamayan rastgele niceliklerin etkilerindendir. Rastlantısal hatalar, standart sapmalar ve dağılım eğrileri ile tanımlanmaktadır. Üçüncüsü, sürüklenme hataları, kontrol edilemeyen niceliklerin sistematik etkilerinden kaynaklanmaktadır. Genelde bir zaman etkisi ya da aşınma etkisi söz konusudur. Sürüklenme ünitenin zamanla yenilenmesi veya kullanım miktarı değişimiyle karakterize edilebilmektedir [3]. Dördüncüsü, çizgi dışı hatalar ise, ölçme işlemindeki tekrarlanmayan olaylardan ortaya çıkmaktadır. Bunlar için temel sebep yanlış okuma, yazma veya ekipman kullanımı vb. insan kaynaklı hata etkenleridir. Standarda göre, Tip-A belirsizlik bileşenleri tekrarlanan ölçümlerden elde edilen veriye gereksinim duymaktadırlar. Dağılımın standart sapması veya gerçek değerin standart sapması formülle hesaplanabilmektedir (Eşitlik 1).

$\mathrm{S}_{\mathrm{X}}=\sqrt{\frac{1}{\mathrm{n}-1} \sum_{\mathrm{i}=1}^{\mathrm{n}}\left(\overline{\mathrm{X}}-\mathrm{X}_{\mathrm{n}}\right)^{2}}$

Ölçme işlemi standart sapması az sayıda tekrarlı ölçümlerle belirlenmeye çalışıldığı takdirde ya yanlış bir değeri ifade eder ya da çok küçük bir değer bulunur. Bu sebeple bir güvenlik kat sayısı ile çarpılmalıdır.

Yine ilgili standarda göre, Tip-B belirsizlik değerlendirmesinde, standart sapma değerinin istatistiksel olmayan yöntemlerle sıklıkla önceki deneyimlerle sınırlandırılması veya kabaca tahmin edilmesi yöntemleri kullanılır. Deneyimle operatör hata limit değerlerinin değişme miktarı için önceki limit değerlerini anımsamakta veya fizik kurallarını kullanarak ve/veya mantık yürüterek bu değeri belirleyebilmektedir [3].

Literatürde her türlü ölçme işleminde ölçme belirsizliğinin hesaplandığı sayısız çalışma mevcuttur. Bunlardan içerisinde talaşı ı imalat gören yüzeylerden özellikle $R_{a}$ parametresinin de ölçme belirsizliğinin analiz edildiği çok yeni çalışmalarda göze çarpmaktadır [4,5,6].

\section{MATERYAL VE METOT}

\subsection{Materyal}

$\mathrm{Bu}$ çalışmada talaşlı imalat proseslerinden alın frezeleme yöntemi ile elde edilmiş mamulün yüzey pürüzlülüğü ölçümü sırasında ilgili standarda bağlı olarak belirsizlik hesaplaması gerçekleştirilmiştir. Frezelenen paslanmaz çelik malzeme AISI H13 takım çeliğidir. Frezeleme operasyonu işlem parametreleri Çizelge 1'de verilmektedir. Takım AlTiN kaplamalı ve $1.0 \mathrm{~mm}$ uç radyusuna sahiptir.

Çizelge 1. Frezeleme işlem parametreleri

\begin{tabular}{|l|c|c|}
\hline Parametre Adı & Birim & Değeri \\
\hline Kesme Hızı & $\mathrm{m} / \mathrm{dk}$ & 60 \\
\hline Kesme Derinliği & $\mathrm{mm}$ & 0,70 \\
\hline İlerleme & $\mathrm{mm} / \mathrm{diş}$ & 0,1 \\
\hline
\end{tabular}

\subsection{Metod}

Yüzey pürüzlülük ölçme işlemleri için seçilen metot temaslı tip muayenedir. TIME marka, 0.001 $\mu \mathrm{m}$ hassasiyetli, değme iğne uçlu yüzey pürüzlülüğü ölçme cihazı ile yüzey pürüzlülük parametresi $\mathrm{R}_{\mathrm{a}}$ (Aritmetik Ortalama Yüzey Pürüzlülük Değeri) ölçümleri ilgili standartlar çerçevesinde gerçekleştirilmiştir [7,8]. Aritmetik 
ortalama yüzey pürüzlülük parametresi $\mathrm{R}_{\mathrm{a}}$ değeri aynı teknikle ve aynı şartlar altında tekrarlamalı olarak 10 kez ölçülmüştür. Ölçme işlemleri standardize sıcaklık ve bağıl nem koşullarına sahip bir ölçme odasında gerçekleştirilmiştir [9]. Ölçüm yapılan yüzeyin ve ölçme cihazı görüntüleri Şekil 2'de verilmektedir.

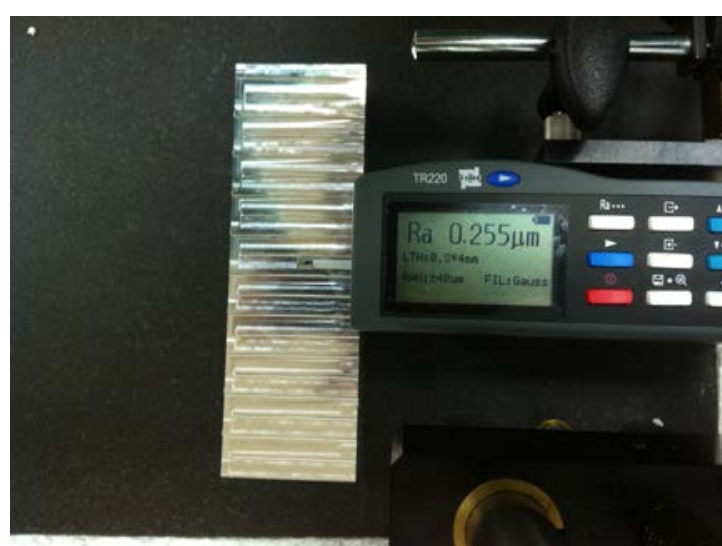

Şekil 2. Ölçümü yapılan yüzey ve ölçme cihazı

\section{BELİRSIZLIKK HESAPLARI}

$\mathrm{Bu}$ çalışma ile ISO GUM rehberi referans alınarak ölçme belirsizliği hesabı gerçekleştirilmiş işleme etkiyen en önemli görülen hata faktörlerinin etki değerleri hesaplanmış ve Çizelge 2'de verilmiştir.

Çizelge 2. Hesaplamaya katılan hata faktörleri

\begin{tabular}{|l|c|}
\hline Hata Faktörü Adı & Değeri \\
\hline Cihazın başlangıç hatası & $0,02 \mu \mathrm{m}$ \\
\hline Kalibrasyon belirsizliği & $0,03 \mu \mathrm{m}$ \\
\hline Ölçme kuvveti belirsizliği & $0,005 \mu \mathrm{m}$ \\
\hline Sistem gürültüsü belirsizliği & $0,005 \mu \mathrm{m}$ \\
\hline Tekrarlanabilirlik / Çözünürlük & $0,01 \mu \mathrm{m}$ \\
\hline
\end{tabular}

Aritmetik ortalama yüzey pürüzlülük parametresi $\mathrm{R}_{\mathrm{a}}$ değerinin tekrarlamalı ölçüm sonuçlarının standart sapma değeri 0,0042 $\mu \mathrm{m}$ olarak hesaplanmıştır.

\subsection{Belirsizlik Hesapları}

$\mathrm{Bu}$ bölümde ölçme işlemleri belirsizlik hesapları verilmektedir.

\subsubsection{Cihazın Başlangıç Hatası}

Cihazın başlangıç hatası olarak cihazın referansın nominal değerinden yaptığı max. sapma, 0,02 $\mu \mathrm{m}$, değeri alınmıştır (Normal Dağılım için $b=0,5$ ) (Eşitlik 2).

$\mathrm{U}_{\mathrm{ML}}=0,02 \mathrm{xb}=0,01 \mu \mathrm{m}$

\subsubsection{Kalibrasyon Belirsizliği}

Cihazın kalibrasyonunda referans elemanının sertifikasından alınan bu değer 0,03 $\mu$ m'dir (Eşitlik 3).

$\mathrm{U}_{\mathrm{MC}}=0,03 \mathrm{xb}=0,015 \mu \mathrm{m}$

\subsection{3. Ölçme Kuvveti Belirsizliği}

Probun yüzeye uyguladığı kuvvetten doğan belirsizlik cihaz imalatçısından alınan değere göre 5 nm’dir (Eşitlik 4).

$$
\mathrm{U}_{\mathrm{MF}}=0,005 \mathrm{x} 0,5=0,0025 \mu \mathrm{m}
$$

\subsubsection{Sistem Gürültüsü Belirsizliği}

Cihazın yarattığı elektriksel gürültünün ölçüm sonucuna etkisi $5 \mathrm{~nm}$ olarak alınmıştır (Normal Dağılım için $b=0,5)$ (Eşitlik 5).

$$
\mathrm{U}_{\mathrm{MN}}=0,005 \mathrm{x} 0,5=0,0025 \mu \mathrm{m}
$$

\subsubsection{Tekrarlanabilirlik/Çözünürlük}

Standartda göre tekrarlanabilirlik ve çözünürlük değerlerinden etkisi daha büyük olan belirsizlik hesabına dahil edilir. Çözünürlük değerinin belirsizlik değerine etkisi hesaplanırken cihazın en küçük ondalık değeri (d) olan 0,001 $\mu \mathrm{m}$ değeri kullanılır (Eşitlik 6).

$\mathrm{U}_{\mathrm{RR}}=\frac{\mathrm{d}}{2 \sqrt{3}}=0,00028 \mu \mathrm{m}$

Tekrarlanabilirlik değerinin belirsizliğe etkisi, tekrarlamalı ölçüm sonuçlarının standart sapma değeri olan 0,0042 $\mu$ m'dir. Bu durumda belirsizlik 
hesabında tekrarlanabilirlik değerinin etkisi kullanılacaktır.

İlaveten, işlemler esnasında $0,3^{\circ} \mathrm{C}$ 'den az olan oda sıcaklığındaki değişim miktarı belirsizlik hesaplamalarında ihmal edilmiştir. Aynı şekilde bağıl nem değeri de toleranslar dahilinde tutulduğundan ihmal edilmiştir. $\mathrm{Bu}$ çalışmada işlemi en fazla etkileyen değerlere sahip olan 5 farklı etki faktörü belirsizlik bütçesi hesabına dahil edilmiştir. Birleşik standart belirsizlik değeri $\left(U_{C}\right)$ için Eşitlik 7 kullanılarak yapılan hesaplama sonucunda 0,01884 $\mu \mathrm{m}$ değeri elde edilmiştir.

$\mathrm{U}_{\mathrm{C}}=\sqrt{\mathrm{U}_{\mathrm{ML}}{ }^{2}+\mathrm{U}_{\mathrm{MC}}{ }^{2}+\mathrm{U}_{\mathrm{MF}}{ }^{2}+\mathrm{U}_{\mathrm{MN}}{ }^{2}+\mathrm{U}_{\mathrm{RR}}{ }^{2}}$

Güvenlik faktörü k=2 alınarak Eşitlik 8'e göre göre hesaplanan genişletilmiş belirsizlik değeri $(U)$ $0,03768 \mu \mathrm{m}$ bulunmuştur.

$U=k x U_{C}$

\subsection{Belirsizlik Bütçesi Tablosu}

Elde edilen hesaplamalara göre hazırlanan belirsizlik bütçesi tablosu Çizelge 3'de verilmektedir.

Çizelge 3. Belirsizlik bütçesi tablosu

\begin{tabular}{|c|c|c|c|c|c|}
\hline 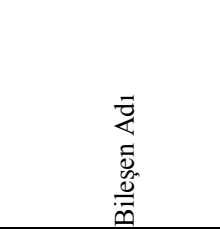 & 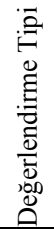 & 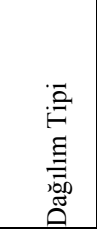 & 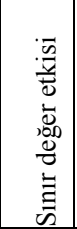 & 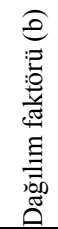 & 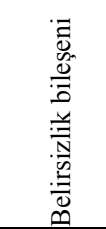 \\
\hline Başlangıç Hatası & $\mathrm{B}$ & Normal & 0,02 & 0,5 & $\overline{0,01}$ \\
\hline $\begin{array}{l}\text { Kalibrasyon } \\
\text { Belirsizliği }\end{array}$ & $\mathrm{B}$ & Normal & 0,03 & 0,5 & 0,015 \\
\hline Ölçme Kuvveti & $\mathrm{B}$ & Normal & 0,005 & 0,5 & 0,0025 \\
\hline Sistem Gürültüsü & $\mathrm{B}$ & Normal & 0,005 & 0,5 & 0,0025 \\
\hline $\begin{array}{l}\text { Tekrarlanabilirlik } \\
(\mathrm{n}=10)\end{array}$ & A & Normal & & & 0,0042 \\
\hline \multicolumn{5}{|c|}{ Birleşik standart belirsizlik $\left(U_{c}\right)(\mu \mathrm{m})$} & 0,01884 \\
\hline \multicolumn{5}{|c|}{ Genişletilmiş belirsizlik $(\mathrm{k}=2)(\mu \mathrm{m})$} & 0,03768 \\
\hline
\end{tabular}

\section{SONUÇLAR}

$\mathrm{Bu}$ çalışma ile ISO GUM rehberi referans alınarak ölçme belirsizliği hesabı gerçekleştirilmiş işleme etkiyen en önemli görülen hata faktörlerinin etkisi ile belirsizlik bütçesi tablosu oluşturulmuştur. Böylece ölçme işlemine etki eden ve hataya sebep olan tüm faktörlerin etkisinin en az seviyeye indirmek mümkün olmakta ve ölçme işleminin doğruluğunun yüksek olduğu kanıtlanmaktadır. Bu uygulama için ölçme belirsizliği hakkındaki müşteri beklentisi $0,04 \mu \mathrm{m}$ olduğundan ölçme belirsizliğimizin müşteri beklentilerini karşıladığını yani sonuçlarımızın doğruluğunun talepleri sağlayacak değerde yüksek olduğunu söyleyebiliriz. Ölçme sonuçlarınız ilgili standartların gereklerini karşıladığından güvenilirdir.

$\mathrm{Bu}$ çalışma aynı zamanda birleşik standart belirsizlik değeri hesaplamak ve belirsizlik bütçesi tablosu oluşturmak isteyen araştırmacı ve uygulayıcılar için incelemeye değerdir. Bu çalışma aynı zamanda, metroloji ve kalite yönetimi alanlarında, endüstride gerçekleştirilen ölçme işlemlerinin güvenilirliğinin arttırılması ve uluslararası kabul görmesi açısından izlenmesi gereken standardize yolları bir rehber niteliğinde açıkladığından önemlidir. Ölçme belirsizlik değeri müşteri talepleri doğrultusunda gerçekleşmeyen hiçbir ölçme işlemi kabul edilebilir değildir. Belirsizlik tahminleri müşterinin talepleri ve mevcut metrolojik unsurların kapasiteleri doğrultusunda ancak metrolojik hizmeti sunanla müşterisi tarafindan birlikte tahmin edildiğinde gerçekçi değerlere ulaşabilmektedir.

\section{KAYNAKLAR}

1. ISO 10012, 2003. Measurement Management Systems-Requirements for Measurement Processes and Measuring Equipment.

2. JCGM 200: 2008 International Vocabulary of Metrology-Basic and General Concepts and Associated Terms (VIM).

3. ISO 14253-2, 2011. Geometrical Product Specifications (GPS)- Inspection by Measurement of Workpieces and Measuring Equipment Part 2: Guidance for the Estimation of Uncertainty in GPS Measurement, in Calibration of Measuring Equipment and in Product Verification. 
4. Song, J., Renegar, T.B., Soons, J., Muralikrishnan, B., Villarrubia, J., Zheng, A., Vorburger, T.V., 2014. The Effect of Tip Size on the Measured Ra of Surface Roughness Specimens with Rectangular Profiles, Precision Engineering, 38(1), 217-220.

5. Leo Kumar, S.P., 2018. Experimental Investigations and Empirical Modeling for Optimization of Surface Roughness and Machining Time Parameters in Micro end Milling Using Genetic Algorithm, Measurement, 124, 386-394.

6. Leo Kumar, S.P., 2019. Measurement and Uncertainty Analysis of Surface Roughness and Material Removal Rate in Micro Turning Operation and Process Parameters Optimization, Measurement, 140, 538-547.

7. ISO 25178-601, 2010. Geometrical Product Specifications (GPS)-Surface Texture: ArealPart 601: Nominal Characteristics of Contact (Stylus) Instruments.

8. ISO 25178-602, 2010. Geometrical Product Specifications (GPS)-Surface Texture: ArealPart 602: Nominal Characteristics of NonContact (Confocal Chromatic Probe) Instruments.

9. ISO 1, 2016. Geometrical Product Specifications (GPS)-Standard Reference Temperature for the Specification of Geometrical and Dimensional Properties. 